\title{
Vitamin D and family history of hypertension in relation to hypertension status among college students
}

\author{
Yendelela L. Cuffee $\mathbb{D}^{1 凶}$, Ming Wang ${ }^{2}$, Nathaniel R. Geyer $\mathbb{D}^{2}$, Sangeeta Saxena ${ }^{2}$, Suzanne Akuley ${ }^{2}$, Lenette Jones ${ }^{3}$ and $^{4}$ \\ Robin Taylor Wilson (iD) ${ }^{4}$
}

(c) The Author(s) 2021

Hypertension and vitamin D concentrations have heritable components, although these factors remain uninvestigated in young adults. The objective of this study was to investigate hypertension risk among young adults with respect to family history of hypertension, adjusting for vitamin D status. Resting blood pressure (BP) was measured in 398 individuals aged 18-35 and classified according to the 2017 American Heart Association criteria. Plasma vitamin D metabolite $\left(25(\mathrm{OH}) \mathrm{D}_{3} ; 24,25(\mathrm{OH})_{2} \mathrm{D}_{3} ; 1,25(\mathrm{OH})_{2} \mathrm{D}_{3}\right)$ concentrations were determined using liquid chromatography tandem mass spectrometry (LC-MS/MS). Stepwise logistic regression was used to select covariates. Participants' mean age was 21,30.3\% had hypertension, and nearly all unaware of their hypertensive status (90.7\%). Compared with no parental history, the adjusted odds ratio (AOR) for hypertension was elevated among participants with two parents having hypertension ( $\mathrm{AOR}=4.5,95 \% \mathrm{Cl}: 1.70-11.76)$, adjusting for sex, body mass index, physical activity, and plasma $25(\mathrm{OH}) \mathrm{D}_{3}$. Results for systolic hypertension $(\mathrm{SH})$ were similar but more extreme (two parents $\mathrm{AOR}=7.1,95 \% \mathrm{Cl}$ : $2.82,17.66$ ), although dihydroxy metabolites $\left(1,25(\mathrm{OH})_{2} \mathrm{D}_{3}\right.$ and $\left.24,25(\mathrm{OH})_{2} \mathrm{D}_{3}\right)$ were significant. There was a strong, independent association with dual parental history and hypertension status, regardless of vitamin $D$ status. Hypertension was prevalent in nearly one-third of the sample and underscores the need for targeted prevention for young adults.

Journal of Human Hypertension (2022) 36:839-845; https://doi.org/10.1038/s41371-021-00577-6

\section{INTRODUCTION}

The 2017 Guidelines for the Prevention, Detection, Evaluation and Management of High Blood Pressure from the American College of Cardiology (ACC) and American Heart Association (AHA) reported 103.3 million adults have hypertension [1]. In spite of the increasing prevalence of hypertension in the United States among young adults, a majority of programs and initiatives to reduce high blood pressure have been targeted at middle aged and older adults. The growing prevalence of hypertension among young adults is typically attributed to lifestyle factors such as diet and exercise [1]. Despite the risk of developing hypertension, young adults are often unaware of their hypertension status and less likely to have controlled hypertension. Findings from the 2019 Heart Disease and Stroke Statistics indicated that among 20-39year olds approximately $42 \%$ were aware of their diagnosis, $21 \%$ were being treated, and $10 \%$ had controlled hypertension. The findings indicated the rates of awareness of hypertension status were lowest among young adults (20-39) compared to other age groups [1, 2]. To appropriately diagnose, treat, and reduce the rates of incident hypertension among young people, it is essential to have a comprehensive understanding of the risk factors for elevated and high blood pressure within this age group.

Family history of hypertension is a risk factor for hypertension among children and young adults [3, 4]. A family history of high blood pressure is associated with an increased risk of developing hypertension, earlier onset hypertension, and adverse outcomes from hypertension [4]. Findings from the Framingham Heart Study (FHS) highlighted the importance of the familial history of high blood pressure. The results from the FHS indicated the odds of having hypertension were three times greater for offspring that had two parents with early onset of hypertension [4].

There is a growing interest in examining vitamin $D$ biomarkers and the risk for cardiovascular disease $[5,6]$. Low plasma vitamin D levels (i.e., $<60 \mathrm{nmol} / \mathrm{L}$ ) are a risk factor for developing cardiovascular diseases such as stroke and myocardial infarction [7]. Vitamin D depletion activates the renin-angiotensin-aldosterone system, and the activation of this system increases the risk of developing arterial hypertension $[8,9]$. There are over 50 known biomarkers of vitamin $\mathrm{D}$, but $25(\mathrm{OH}) \mathrm{D}_{3}[10,11]$, is most commonly used to assess vitamin $\mathrm{D}$; and has been used for multiple cross-sectional and retrospective case-control studies [7]. Few studies have examined the relationship between vitamin $D$ and family history of cardiovascular disease. Khalili et al conducted a study of 139 adults after acute myocardial infarction, to examine vitamin D concentration and cardiovascular disease, their findings revealed low 25(OH)D levels were associated with a positive family history of CVD [12]. Circulating blood concentrations of vitamin D may also have a direct role in metabolic syndrome, hypertension, and insulin resistance $[13,14]$, but the association among young adults remains unclear.

\footnotetext{
${ }^{1}$ Epidemiology Program, College of Health Sciences, University of Delaware, Newark, DE, USA. ${ }^{2}$ Department of Public Health Sciences, College of Medicine, Pennsylvania State University, Hershey, PA, USA. ${ }^{3}$ University of Michigan, School of Nursing, Ann Arbor, MI, USA. ${ }^{4}$ Department of Epidemiology and Biostatistics, College of Public Health, Temple

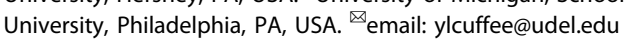

Received: 13 January 2021 Revised: 22 June 2021 Accepted: 5 July 2021

Published online: 20 July 2021 
To date, few studies have explored potential risk factors for developing hypertension such as plasma vitamin $D$ levels and family history among young adults. Given the low rates of hypertension awareness, treatment, and control among young adults, identifying risk factors for the elevated and high blood pressure may be helpful for raising awareness about hypertension and hypertension management. Early identification of risk factors can provide access to primary prevention efforts, such as lifestyle and behavioral change, and provide opportunities to tailor hypertension interventions for young adults, which may help to reduce the risk of cardiovascular disease later in life [15]. The objective of this study was to examine the prevalence of high and elevated blood pressure among young adults and explore family history and plasma vitamin $D$ as potential risk factors for hypertension.

\section{SUBJECTS AND METHODS \\ Study population}

The data for this study were obtained during multiple data collection periods of the Sunlight Nutrition, Skin, and Human Ancestry related to vitamin D Exposure and Synthesis (SuNSHADES) Study, as previously described [16]. SuNSHADES was conducted during non-summer months in three waves as follows: Wave 1-February 2006-February 2007; Wave 2February-May 2009, and Wave 3-November 2013-April 2016. Study participants were recruited from Penn State University using institutional list serves, newspapers, and personal interactions. All study participants consented to participate in the study. Participants with hypotension, diabetes, currently taking antihypertensives, steroids, race/ethnicity, or with missing information on vitamin $D$ biomarker concentrations were excluded from the current study, in total 65 participants were excluded from the study. During a single clinic visit to the Penn State Clinical Research Center, participants completed a questionnaire which included gender, age, race/ethnicity, and family history of high blood pressure, BMI, and latitude at the city of birth. Height and weight were measured using the National Health and Nutrition Examination Survey (NHANES) protocol. Standing height was measured in meters using a stadiometer with a fixed vertical backboard and an adjustable head piece. Participants were correctly positioned and weighed in kilograms using a digital weight scale. Individuals were encouraged to bring in all medications for recording purposes. The dose for oral contraceptives (ethinyl estradiol ug/day), hypertensive medication use and antidepressant use was classified using the Prescriber's Digital Reference (www.pdr.net). At the time of the visit, all individuals were made verbally aware of their blood pressure status by the attending study nurse and provided hardcopy materials on high blood pressure risks from the Centers for Disease Control and Prevention. All waves of the study were approved by the Pennsylvania State College of Medicine IRB Protocol Number 22524 (Waves 1 and 2) and 43010 (Wave 3).

\section{Outcome measurements}

Blood pressure was measured following the NHANES protocol by clinical research nurses trained in the protocol and were consistent across each time period data were collected [17]. In brief, two consecutive blood pressure measurements were taken after the participant was seated for 5 min. Using the arithmetic mean of systolic and diastolic, four categories of blood pressure were determined: normal (systolic $<120 \mathrm{mmHg}$ and diastolic $<80 \mathrm{mmHg}$ ), elevated (systolic $120-129 \mathrm{mmHg}$ and diastolic $<80 \mathrm{mmHg}$ ), hypertension stage 1 (systolic $130-139 \mathrm{mmHg}$ or diastolic $80-89 \mathrm{mmHg}$ ) and hypertension stage 2 (systolic $\geq 140 \mathrm{mmHg}$ or diastolic $\geq 90 \mathrm{mmHg}$ ) in accordance with the 2017 ACC/AHA/AAPA/ABC/ACPM/AGS/ APhA/ASH/ASPC/NMA/PCNA Guideline for the Prevention, Detection, Evaluation, and Management of High Blood Pressure in Adults [18-20].

\section{Vitamin D biomarkers}

Four plasma vitamin $\mathrm{D}$ biomarkers $25(\mathrm{OH}) \mathrm{D}_{3}, 25(\mathrm{OH}) \mathrm{D}_{2}, 24,25(\mathrm{OH})_{2} \mathrm{D}_{3}$, and $1,25(\mathrm{OH})_{2} \mathrm{D}_{3}$ were measured using liquid chromatography with tandem mass spectrometry (LC/MS-MS) as described previously [16]. The lower limit of quantitation (LLOQ) for $25(\mathrm{OH}) \mathrm{D}_{3}, 25(\mathrm{OH}) \mathrm{D}_{2}, 24,25(\mathrm{OH})_{2} \mathrm{D}_{3}$ metabolites was $10 \mathrm{pg} / \mathrm{mL}$, with a linear range of $1-100 \mathrm{ng} / \mathrm{mL}$ for 25 $(\mathrm{OH}) \mathrm{D}_{2}$ and $25(\mathrm{OH}) \mathrm{D}_{3}$ and $0.1-10 \mathrm{ng} / \mathrm{mL}$ for $24,25(\mathrm{OH})_{2} \mathrm{D}_{3}$ [16]. For 1,25
$(\mathrm{OH})_{2} \mathrm{D}_{3}$, the lower limit of quantitation (LLOQ) is $5 \mathrm{pg} / \mathrm{mL}$ with a linear range of 5 to $1000 \mathrm{pg} / \mathrm{mL}$ (Dai, 2015). The percent coefficient of variation, assayed in 10 repeated samples of pooled plasma from healthy individuals on separate days, was $2.7,12.2$, and 6.3 for $25(\mathrm{OH}) \mathrm{D}_{3}, 25(\mathrm{OH}) \mathrm{D}_{2}, 24,25$ $(\mathrm{OH})_{2} \mathrm{D}_{3}$, respectively. Because $25(\mathrm{OH}) \mathrm{D}_{2}$ is predominantly associated with environmental (dietary and supplement intake) and not genetic factors; therefore, we did not include $25(\mathrm{OH}) \mathrm{D}_{2}$ in the analysis.

\section{Genotyping and genetic ancestry}

DNA was extracted from whole blood in tubes with ethylenediaminetetraacetic acid using aQIAamp DNAMini Kit (Qiagen Sciences, Germantown, Maryland) and stored at $-80^{\circ} \mathrm{C}$. A panel of 112 ancestry-informative markers was used to estimate the proportion of West-African ancestry and proportion of European ancestry, using the STRUCTURE algorithm and frequencies inHapMapYRI (WestAfrican) and CEU(European) trios [21, 22]. This panel exhibits high agreement with other ancestry panels (concordance correlation coefficient $=0.97)$. Genotypes were determined using the Illumina BeadXpress assay (Illumina Inc., San Diego, California). Genotyping cluster algorithm outputs were visually inspected, and genotyping calls were adjudicated by laboratory personnel blinded to the vitamin D status and study characteristics of participants. Samples and assays with $>10 \%$ unreadable genotyping calls were excluded from the analysis.

\section{Statistical methods}

BMI was calculated as weight in kilograms over height in meters squared $\left(\mathrm{kg} / \mathrm{m}^{2}\right)$ and classified according to the World Health Organization (2000) BMI Classification [16]. Quartiles of vitamin D biomarkers were determined and classified according to quartile cut-off values among normotensive participants. Participants with missing BMI, physical activity, and/or smoking status were excluded from the analysis. Two-tailed student's $t$ and chi-square tests were used to test for (unadjusted) bivariate differences in continuous and categorical variables, respectively. Bivariate tests for trend in categorical variables with respect to normotensive, elevated blood pressure and hypertensive status were calculated using the Mantel-Haenszel chi-square. Bivariate tests for trend among quantitative variables with respect to normotensive, elevated blood pressure, and hypertensive status were calculated using linear regression (SAS Proc REG).

\section{Multiple regression model}

Potential confounding variables were assessed using stepwise selection in logistic regression for (1) the odds of hypertension (versus normotension), i.e., excluding those with elevated blood pressure; (2) the odds high systolic blood pressure; and (3) the odds of high diastolic blood pressure. Those variables with a bivariate $p$-value of 0.150 or less were placed into a stepwise selection model ( $p=0.150$ to enter, $p=0.100$ to stay in the model). For purposes of comparison, the same adjustment variables found in association with hypertension were also used in the multiple regression model of the odds of elevated blood pressure (versus normotension). In order to assess possibility of collinearity of the adjustment variables, Spearman Correlation coefficients were calculated for all variables included in the final models. All $p$-values were two-sided, $p=\leq 0.05$ was considered statistically significant, and all analyses were performed using SAS 9.4.

\section{RESULTS}

\section{Bivariate associations}

After applying exclusion criteria, the analysis included 396 young adults from all three waves of the study (Supplemental Fig. 1). In bivariate analyses, elevated blood pressure status and hypertension status were significantly associated with sex, parental history of hypertension (both parents), self-reported history or hypertension, parental history of diabetes (neither parent), and body mass index (all $p=<0.05$, Table 1). Vitamin D biomarkers $\left(1,25(\mathrm{OH})_{2} \mathrm{D}_{3}\right.$ and $24,25(\mathrm{OH})_{2} \mathrm{D}_{3}$ ) were negatively associated both with elevated blood pressure and hypertension status (all $p=<0.010$, Table 2). Both $1,25(\mathrm{OH})_{2} \mathrm{D}_{3}$ and $24,25(\mathrm{OH})_{2} \mathrm{D}_{3}$, monotonically decreased from normotensive, elevated blood pressure, and hypertensive group status, although this was not the case for $25(\mathrm{OH}) \mathrm{D}_{3}$ which had similar (and lower) values for elevated and hypertensive 
Table 1. Characteristics of study participants by blood pressure status, adults ages 18-35, Centre County Pennsylvania, 2006-2016.

\begin{tabular}{|c|c|c|c|c|c|}
\hline & Normotensive $\boldsymbol{N}(\%)$ & Elevated $\boldsymbol{N}(\%)$ & Hypertensive Stage I and II N (\%) & Total $N(\%)$ & $p$-trend \\
\hline Total & $238(100.0)$ & $38(100.0)$ & $120(100.0)$ & $396(100.0)$ & \\
\hline Female & $168(70.6)$ & $15(39.5)$ & $54(45.0)$ & $237(59.9)$ & $<0.001$ \\
\hline \multicolumn{6}{|l|}{ Race/ethnicity } \\
\hline White, non-hispanic & $113(47.5)$ & $11(29.0)$ & $52(43.3)$ & $176(44.4)$ & 0.339 \\
\hline Black, non-hispanic & $109(45.8)$ & $26(68.4)$ & $64(53.3)$ & $199(50.3)$ & 0.112 \\
\hline Hispanic/Latinx & $16(6.7)$ & $1(2.6)$ & $4(3.3)$ & $21(5.3)$ & 0.154 \\
\hline Both Parents & $13(5.5)$ & $9(23.7)$ & $15(12.5)$ & $37(9.3)$ & 0.013 \\
\hline Mother Only & $38(16.0)$ & $7(18.4)$ & $21(16.7)$ & $66(16.4)$ & 0.837 \\
\hline Father Only & $54(22.7)$ & $6(15.8)$ & $29(24.2)$ & $90(22.5)$ & 0.840 \\
\hline Parent status unknown/missing & $5(2.1)$ & $1(2.6)$ & $3(2.5)$ & $9(2.3)$ & 0.799 \\
\hline \multicolumn{6}{|l|}{ Parental history of diabetes } \\
\hline Neither parent & $198(83.2)$ & $31(81.6)$ & $88(73.3)$ & $317(80.1)$ & 0.031 \\
\hline Both parents & $1(0.4)$ & $0(0.0)$ & $2(1.7)$ & $3(0.8)$ & - \\
\hline Mother only & $12(5.0)$ & $4(10.5)$ & $8(6.7)$ & $24(6.1)$ & 0.463 \\
\hline Father only & $22(9.2)$ & $3(7.9)$ & $19(15.8)$ & $44(11.1)$ & 0.074 \\
\hline Parent status unknown/missing & $5(2.1)$ & $0(0.0)$ & $3(2.5)$ & $8(2.0)$ & - \\
\hline \multicolumn{6}{|l|}{ Current smoking status } \\
\hline Never & $212(89.1)$ & $36(94.7)$ & $98(81.7)$ & $346(87.4)$ & 0.068 \\
\hline Former & $18(7.6)$ & $2(5.3)$ & $13(10.8)$ & $33(8.3)$ & 0.331 \\
\hline Current & $8(3.4)$ & $0(0.0)$ & $9(7.4)$ & $17(4.3)$ & 0.096 \\
\hline \multicolumn{6}{|l|}{ Body mass index (BMI) class } \\
\hline Underweight & $7(2.9)$ & $0(0.0)$ & $2(1.7)$ & $9(2.3)$ & - \\
\hline Normal & $170(71.4)$ & $21(55.3)$ & $49(40.8)$ & $240(60.6)$ & $<0.001$ \\
\hline Overweight & 47 (19.8) & $8(21.1)$ & $38(31.7)$ & $93(23.5)$ & 0.014 \\
\hline Obese & $14(5.9)$ & $9(23.7)$ & $31(25.8)$ & $54(13.6)$ & $<0.001$ \\
\hline Alcohol use (>1 drink per week) & $50(21.0)$ & $8(21.1)$ & $24(19.8)$ & $82(20.6)$ & 0.830 \\
\hline Antidepressant use & $17(7.1)$ & $4(10.5)$ & $14(11.7)$ & $35(8.8)$ & 0.146 \\
\hline Coffee intake ( $>1$ cup per week) & $85(35.7)$ & $9(23.7)$ & $33(27.5)$ & $127(32.1)$ & 0.092 \\
\hline Oral contraceptive use (women) & $56(33.3)$ & $5(33.3)$ & $19(35.2)$ & $80(33.8)$ & 0.809 \\
\hline
\end{tabular}

*One individual with unknown smoking status reclassified as 'never smoker'-cell sizes too small for $P$-value trend calculation.

groups $(59.4 \mathrm{nmol} / \mathrm{L}$ and $60.2 \mathrm{nmol} / \mathrm{L}$, respectively) when compared with normotensive individuals. We did not detect a statistically significant association between West African genetic ancestry proportion and elevated blood pressure/hypertension status ( $p$-trend $=0.337$ ). Individuals classified with hypertension had a mean systolic blood pressure of $123.8( \pm 10.3) \mathrm{mmHg}$ and a mean diastolic blood pressure of $83.6( \pm 5.4) \mathrm{mmHg}$ (Table 2). Neither paternal nor maternal history of kidney stones, obesity, or a thyroid disorder were associated with the likelihood of hypertension in bivariate tests of association (data not shown).

\section{Variable selection}

The following variables with a bivariate $p$-value of 0.150 or less were entered into the stepwise selection models: coffee intake indicator variable for $>1$ cup per week), gender (female v. male), body mass index (as WHO BMI Class), physical activity (none/ unknown, a few times per month, 1-3 days per week, 4-6 days per week, daily), smoking (never, former, current smoking), current antidepressant use (yes/no), current oral contraceptive (OC) use (yes/no), daily OC dose of ethinyl estradiol (ug/day, continuous), number of days after summer solstice at the time of blood draw 
Table 2. Mean West African genetic ancestry proportion, vitamin D biomarkers, days after summer solstice at blood draw, body mass index and blood pressure among young adults (ages 18-35), by hypertension stage, Centre County Pennsylvania, 2006-2016.

\begin{tabular}{|c|c|c|c|c|c|}
\hline & $\begin{array}{l}\text { Normotensive } \\
\text { mean (SD) }\end{array}$ & $\begin{array}{l}\text { Elevated blood } \\
\text { pressure mean (SD) }\end{array}$ & $\begin{array}{l}\text { Hypertensive (Stage I and } \\
\text { II) mean (SD) }\end{array}$ & $p$-trend & Spearman's $R^{2}$ \\
\hline $\begin{array}{l}\text { West African Genetic Ancestry } \\
\text { Proportion }\end{array}$ & $39.6(34.8)$ & $51.1(32.5)$ & $42.6(35.6)$ & 0.337 & 0.002 \\
\hline $25(\mathrm{OH}) \mathrm{D}_{3}(\mathrm{nmol} / \mathrm{L})$ & $76.8(54.7)$ & $59.4(35.2)$ & $60.2(32.0)$ & $<0.001$ & 0.027 \\
\hline $24,25(\mathrm{OH})_{2} \mathrm{D}_{3}(\mathrm{nmol} / \mathrm{L})$ & $10.1(10.0)$ & $7.0(5.9)$ & $6.5(5.6)$ & $<0.001$ & 0.039 \\
\hline $1,25(\mathrm{OH})_{2} \mathrm{D}_{3}(\mathrm{pmol} / \mathrm{L})$ & $101.9(38.4)$ & $95.0(44.5)$ & $90.2(29.1)$ & 0.004 & 0.021 \\
\hline Body Mass Index & $23.9(3.9)$ & $28.1(6.9)$ & $28.1(7.0)$ & $<0.001$ & 0.119 \\
\hline $\begin{array}{l}\text { Systolic blood } \\
\text { pressure }(\mathrm{mmHg})\end{array}$ & $108.5(6.2)$ & $122.7(2.8)$ & $123.8(10.3)$ & $<0.001$ & 0.460 \\
\hline $\begin{array}{l}\text { Diastolic blood } \\
\text { pressure }(\mathrm{mmHg})\end{array}$ & $70.9(4.9)$ & $72.1(6.2)$ & $83.6(5.4)$ & $<0.001$ & 0.515 \\
\hline
\end{tabular}

IU International Units, SD standard deviation, $\mathrm{kg}$ kilograms, $\mathrm{m}^{2}$ meters squared, $n$ mol nanomoles, $L$ liters, $m g$ milligrams, $d L$ deciliter, $B M I$ body mass index (BMI), West African Ancestry, and Vitamin D Biomarkers $P$-values were log transformed for this analysis.

(quartile in the entire study population), and parental history of diabetes (for both parents, mom only, dad only, and unknown). In the model of hypertension (versus normotension), stepwise selection retained female sex, body mass index (normal weight and obese indicators), physical activity (none), anti-depressant use (yes), and one vitamin $D$ biomarker $\left(25(\mathrm{OH}) \mathrm{D}_{3}\right)$ as potential adjustment variables (all $p=<0.100$, hypertensive vs. normotensive). After inclusion of parental history of hypertension in the model, the variables for sex, body mass index, physical activity, and $25(\mathrm{OH}) \mathrm{D}_{3}$ remained statistically significant and were therefore retained in the final model (all $p<0.05$ ). Antidepressant use was of borderline statistical significance $(p=0.067, \mathrm{AOR}=2.3(95 \% \mathrm{Cl}$ : $0.94,5.78)$, adjusting for all variables listed above and was not retained in the final model. Among all variables in the final model for hypertension (normotensive vs. hypertensive), the absolute value of spearman correlation coefficients were all less than or equal to 0.28 , with spearman correlation coefficients greatest between female sex and quartile 4 of $25(\mathrm{OH}) \mathrm{D}_{3}$ (rho $=-0.25, p=$ $<0.001$, and between no physical activity and unknown parental status of hypertension ( $r$ o $=+0.19, p=0.001$ ), data not shown.

In the model of hypertension (normotensive vs. systolic and diastolic hypertension), stepwise selection retained female sex, body mass index, physical activity, anti-depressant use, smoking status, number of days from summer solstice, and two vitamin D biomarkers $\left(1,25(\mathrm{OH}) \mathrm{D}_{3}\right.$ and $\left.24,25(\mathrm{OH})_{2} \mathrm{D}_{3}\right)$. After inclusion of parental history of hypertension in the model, the variables for sex, body mass index, physical activity, anti-depressant use and $1,25(\mathrm{OH})_{2} \mathrm{D}_{3}$ and $24,25(\mathrm{OH})_{2} \mathrm{D}_{3}$ remained statistically significant and were therefore retained in the final model (all $p<0.05$ ). Among all variables in the final model for hypertension, the absolute value of spearman correlation coefficients were all less than 0.30 in magnitude with the greatest correlation occurring between female sex and systolic and diastolic hypertension (rho $=-0.30)$.

\section{Final model results}

The odds of hypertension were significantly elevated among individuals reporting both parents having a history of hypertension ( $\mathrm{AOR}=4.5,95 \% \mathrm{Cl}$ : 1.70-11.76), following adjustment for sex, body mass index, physical activity, and plasma concentration of 25 $(\mathrm{OH}) \mathrm{D}_{3}$ (Table 3). Overall, these variables explained approximately $21 \%$ of the variability in hypertensive (versus normotensive) status
$\left(R^{2}=0.210\right)$. The odds of systolic hypertension (versus no systolic hypertension) was also significant among individuals reporting both parents having a history of hypertension (AOR $=7.1,95 \% \mathrm{Cl}$ : 2.82, 17.66), following adjustment for sex, body mass index, physical activity, anti-depressant use and plasma concentrations of $1,25(\mathrm{OH})_{2} \mathrm{D}_{3}$ and $24,25(\mathrm{OH})_{2} \mathrm{D}_{3}$. Overall, these variables explained about $27 \%$ of the variability in systolic hypertension $\left.R^{2}=0.267\right)$. In the diastolic hypertension model was significant among those overweight, antidepressant use, and concentrations of $25(\mathrm{OH}) \mathrm{D}_{3}$ and $24,25(\mathrm{OH})_{2} \mathrm{D}_{3}$. There was no evidence of significant lack of fit of either logistic regression model $(\mathrm{H}-\mathrm{L} p$ value $=0.841$ and 0.269 , respectively). Self-reported dual parental history of hypertension was also significantly associated with elevated blood pressure (v. normotension), after adjustment for sex, body mass index, physical activity, and plasma concentration of $25(\mathrm{OH}) \mathrm{D}_{3}$ (Supplemental Table 1).

\section{DISCUSSION}

Self-reported dual parental history of hypertension was positively associated both with elevated blood pressure, overall hypertension, and systolic hypertension among healthy young adult participants (ages 18-35). The magnitude of association with both parents having hypertension was substantial, ranging from 4.5-fold for overall hypertension to 7.1-fold for systolic hypertension. Parental hypertension status was not associated with elevated diastolic blood pressure. Our results are similar to previous studies, which report a 2.2-fold to 11 -fold elevated risk $[23,24]$. Forty percent of healthy young adult volunteers on this university campus were classified as either having elevated blood pressure or hypertension, based upon the 2017 ACC/AHA Hypertension Guidelines classification. Among those found to be hypertensive, nearly all (90.7\%) were unaware of their status. Family history has long been known to be a risk factor for hypertension [4, 24-27] and only about $2 \%$ of participants in this study reported not knowing their family history. The lack of awareness of self-status of hypertension, in spite of knowing parental status, underscores a gap in clinical knowledge translation. This study was conducted among volunteers and therefore may not be representative of either the campus population or university students in general. Nationwide, young adults ages 18-39 years old in the US report a prevalence of self-awareness of 
Table 3. Adjusted odds of hypertension, systolic, and diastolic hypertension, young African American and European American Adults, Centre County Pennsylvania, 2006-2016.

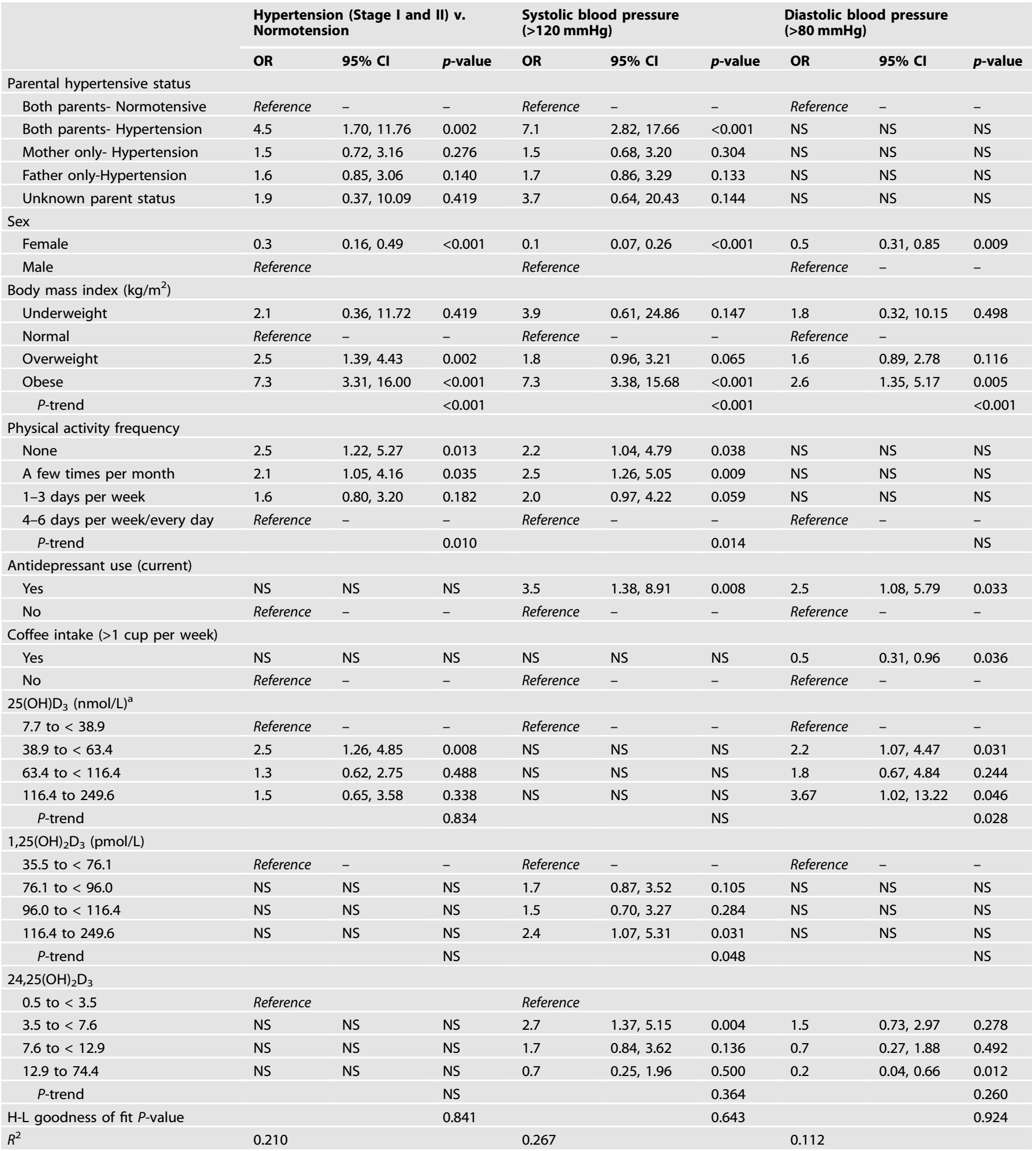

Each model adjusted for all variables shown in the table. $R^{2}$ calculated using linear regression using SAS Proc Rec.

NS not statistically significant and excluded from the mode.

${ }^{a}$ Quartile cut-offs determined according to the distribution among normotensive individuals in the study. Both models include parental hypertension status, sex, body mass index, physical activity. 
hypertension from $52.1 \%$ to $74.7 \%$ in $1999-2000$ and $2013-2015$, respectively [2]. Nonetheless, the lack of awareness among volunteers alone is noteworthy and suggests that our efforts to inform students of their status as part of the study protocol participation were worthwhile.

To date, only a handful of studies have examined vitamin D and family history as risk factors for cardiovascular disease among young adults. Two other studies report an increased likelihood of hypertension among adolescents with at least one hypertensive parent, compared to adolescents that do not have a hypertensive parent $[28,29]$. In a study conducted among adolescents aged 13-19 years old within the Korean National Health and Nutrition Examination Survey, those with a family history of hypertension had a three-fold risk of high blood pressure [30]. Bloetzer et al. conducted a study of 5207 children between the ages of 10-14 in Switzerland [28] wherein children with parents with hypertension had a two-fold risk of hypertension, compared to children that had parents without a history of hypertension. The prevalence of isolated systolic hypertension (ISH) among young adults ages 18-39 is low (less than 3\%) in the US, although ISH prevalence in this age group has roughly tripled since 1988 [31]. Our study was not sufficiently large enough to investigate ISH, however, we did find evidence that dual parental family history is strongly associated ( 7-fold) with systolic hypertension $(>120 \mathrm{mmHg})$, regardless of diastolic blood pressure level. To our knowledge, no previous studies have adjusted for vitamin $D$ status in the investigation of risk associated with a family history of hypertension.

Circulating blood concentrations of $25(\mathrm{OH}) \mathrm{D}_{3}$ have a moderately high heritability (heritability index range $0.69-0.86$ ) according to adolescent twin studies [32]. We therefore hypothesized that, because of the heritability of circulating vitamin $D$ concentrations, that the association with family history would be muted upon adjustment for vitamin D status. However, this was not the case. Our results are consistent with previous studies reporting increased risk of hypertension according to male sex, low physical activity, higher body mass index, antidepressant use and blood concentrations of $25(\mathrm{OH}) \mathrm{D}_{3}$ [33-36]. The association we observed with $25(\mathrm{OH}) \mathrm{D}_{3}$ was not linear in relation to hypertension. Notably, although West African genetic ancestry is a well-known determinant of $25(\mathrm{OH}) \mathrm{D}_{3}$ concentrations [16] it was not associated with hypertension in this study. Non-linear associations with 25 $(\mathrm{OH}) \mathrm{D}_{3}$ and hypertension have been previously reported in metaanalyses [37]. In addition, oral contraceptive use can increase 25 $(\mathrm{OH}) \mathrm{D}_{3}$ concentrations by as much as $25 \%$ in both observational studies and dosing trials (11). The association with the dihydroxyvitamin $D$ metabolites $\left(1,25(\mathrm{OH})_{2} \mathrm{D}_{3}\right.$ and $\left.24,25(\mathrm{OH})_{2} \mathrm{D}_{3}\right)$ with systolic hypertension (and not overall hypertension) is interesting to note and might be explained by the fact that the kidney is the body's major source of hydroxylation for these two circulating metabolites, although only the linear test for trend for $1,25(\mathrm{OH})_{2} \mathrm{D}_{3}$ was not statistically significant. Chronic kidney disease is more strongly associated with systolic blood pressure than diastolic blood pressure [38]. It is also known that reduced production of these dihydroxy-vitamin $\mathrm{D}$ metabolites is a hallmark of CKD progression [39].

\section{Strengths and limitations}

This study is one of the first to examine vitamin D and family history together as risk factors for hypertension among young adults following the release of the new ACC/AHA Hypertension Guidelines. The strengths of this study include, use of a clinical research center with personnel trained in nutritional epidemiology and the NHANES measurement protocols, inclusion of a validated panel of West African Genetic Ancestry proportion as an unbiased way to control for possible influences of race/ethnicity, and use of a validated LC/MS-MS assay for determination of multiple vitamin D biomarkers within a study designed to assess vitamin D status [16]. Limitations include the possible misreported family history of hypertension, although if the misreporting is randomly distributed, this reporting error would be expected to depress the OR. Finally, many of the participants in the present study were young adult volunteers attending college, and therefore the findings of this study may not be generalizable to other groups of young adults in the United States. In addition, we did not find a strong association with cigarette smoking, as observed in previous studies. This may be due to the younger age of our study population and the low overall prevalence of smoking ( 13\%).

The findings of this study suggest a strong influence of the dual parental history of hypertension in the development of elevated blood pressure, hypertension, and systolic hypertension among otherwise healthy young adults. Parental history appears to be independent of sex, physical activity, body mass index, and vitamin $D$ status. The overall prevalence of hypertension and elevated blood pressure ( 40\%) and the combined lack of selfawareness of hypertensive status among well-educated healthy young adults underscores the need for targeted primary and secondary prevention efforts.

\section{Summary table}

What is known about the topic?

- Young adults are often unaware of their hypertension status and less likely to have controlled hypertension.

- Family history of hypertension is a risk factor for hypertension among children and young adults.

- Low plasma vitamin D levels are a risk factor for developing cardiovascular diseases such as stroke and myocardial infarction.

What this study adds?

- Dual parental history of hypertension is a risk factor for the development of elevated blood pressure, hypertension, and systolic hypertension among healthy young adults.

- The lack of awareness of hypertension status, in spite of knowing parental status, underscores a gap in clinical knowledge translation.

- The study findings highlighted an independent association with dual parental history and hypertension status, regardless of vitamin $\mathrm{D}$ status.

\section{DISCLAIMER}

The findings of this study have not been published previously and is not under review at another journal.

\section{REFERENCES}

1. Benjamin EJ, Muntner P, Alonso A, Bittencourt MS, Callaway CW, Carson AP, et al. Heart Disease and Stroke Statistics-2019 Update: a report from the American Heart Association. Circulation. 2019;139:e56-e528.

2. Zhang Y, Moran AE. Trends in the prevalence, awareness, treatment, and control of hypertension among young adults in the United States, 1999 to 2014. Hypertension. 2017;70:736-42.

3. Robinson RF, Batisky DL, Hayes JR, Nahata MC, Mahan JD. Significance of heritability in primary and secondary pediatric hypertension. Am J hypertension. 2005;18:917-21.

4. Niiranen TJ, McCabe EL, Larson MG, Henglin M, Lakdawala NK, Vasan RS, et al. Heritability and risks associated with early onset hypertension: multigenerational, prospective analysis in the Framingham Heart Study. Bmj 2017;357:1949.

5. Lauridsen AL, Vestergaard P, Hermann A, Brot $C$, Heickendorff L, Mosekilde $L$, et al. Plasma concentrations of 25-hydroxy-vitamin D and 1, 25-dihydroxyvitamin D are related to the phenotype of Gc (vitamin D-binding protein): a cross- 
sectional study on 595 early postmenopausal women. Calcif tissue Int. 2005;77:15-22.

6. Powe CE, Evans MK, Wenger J, Zonderman AB, Berg AH, Nalls M, et al. Vitamin Dbinding protein and vitamin $\mathrm{D}$ status of black Americans and white Americans. $\mathrm{N}$. Engl J Med. 2013;369:1991-2000.

7. Wang L, Song Y, Manson JE, Pilz S, März W, Michaëlsson K, et al. Circulating 25hydroxy-vitamin $D$ and risk of cardiovascular disease: a meta-analysis of prospective studies. Circulation: Cardiovascular Qual Outcomes. 2012;5:819-29.

8. Ke L, Mason RS, Kariuki M, Mpofu E, Brock KE. Vitamin D status and hypertension: a review. Integr Blood Press Control. 2015;8:13-35.

9. Andersen LB, Przybyl L, Haase N, von Versen-Höynck F, Qadri F, Jørgensen JS, et al. Vitamin $D$ depletion aggravates hypertension and target-organ damage. J Am heart Assoc. 2015;4:e001417.

10. Judd SE, Tangpricha V. Vitamin D deficiency and risk for cardiovascular disease. Am J Med Sci. 2009;338:40-4.

11. Jenkinson C. The vitamin D metabolome: an update on analysis and function. Cell Biochem Funct. 2019;37:408-23.

12. Khalili $H$, Talasaz AH, Salarifar M. Serum vitamin D concentration status and its correlation with early biomarkers of remodeling following acute myocardial infarction. Clin Res Cardiol. 2012;101:321-7.

13. Lind L, Hänni A, Lithell $H$, Hvarfner A, Sörensen $O$, Ljunghall S. Vitamin D is related to blood pressure and other cardiovascular risk factors in middle-aged men. Am J hypertension. 1995;8:894-901.

14. Lee K, Kim J. Serum vitamin D status and metabolic syndrome: a systematic review and dose-response meta-analysis. Nutr Res Pract. 2021;15:329.

15. Shaikh RB, Mathew E, Sreedharan J, Muttappallymyalil J, Al Sharbatti S, Basha SA Knowledge regarding risk factors of hypertension among entry year students of a medical university. J Fam Community Med. 2011;18:124.

16. Wilson RT, Masters LD, Barnholtz-Sloan JS, Salzberg AC, Hartman TJ. Ancestryadjusted vitamin $\mathrm{d}$ metabolite concentrations in association with cytochrome P450 3A polymorphisms. Am J Epidemiol. 2018;187:754-66.

17. (CDC) CfDC. National Health and Nutrition Examination Survey (NHANES). 2007 CDC.gov.

18. Program NHBPE. The seventh report of the Joint National Committee on pre vention, detection, evaluation, and treatment of high blood pressure. 2004

19. Cushman WC, Whelton PK, Fine LJ, Wright JT Jr, Reboussin DM, Johnson KC, et al. SPRINT trial results: latest news in hypertension management. Hypertension. 2016;67:263-5.

20. Whelton PK, Carey RM, Aronow WS, Casey DE, Collins KJ, Dennison Himmelfarb $C$, et al. 2017 ACC/AHA/AAPA/ABC/ACPM/AGS/APhA/ASH/ASPC/NMA/PCNA guideline for the prevention, detection, evaluation, and management of high blood pressure in adults: a report of the American College of Cardiology/American Heart Association Task Force on Clinical Practice Guidelines. J Am Coll Cardiol. 2018;71:e127-e248.

21. Barnholtz-Sloan JS, McEvoy B, Shriver MD, Rebbeck TR. Ancestry estimation and correction for population stratification in molecular epidemiologic association studies. Cancer Epidemiol Biomark Prev. 2008;17:471-7.

22. Pritchard JK, Stephens M, Rosenberg NA, Donnelly P. Association mapping in structured populations. Am J Hum Genet. 2000;67:170-81.

23. Muntner P, Woodward M, Mann DM, Shimbo D, Michos ED, Blumenthal RS, et al. Comparison of the Framingham Heart Study hypertension model with blood pressure alone in the prediction of risk of hypertension: the Multi-Ethnic Study of Atherosclerosis. Hypertension. 2010;55:1339-45.

24. Liu M, He Y, Jiang B, Wang J, Wu L, Wang Y, et al. Association between family history and hypertension among Chinese elderly. Medicine 2015;94:e2226.

25. Goldstein IB, Shapiro D, Weiss RE. How family history and risk factors for hypertension relate to ambulatory blood pressure in healthy adults. J Hypertens. 2008;26:276-83.

26. Lascaux-Lefebvre V, Ruidavets J, Arveiler D, Amouyel P, Haas B, Cottel D, et al. Influence of parental history of hypertension on blood pressure. J Hum hypertension. 1999;13:631-6.

27. Rebbeck TR, Turner ST, Sing CF. Probability of having hypertension: effects of sex history of hypertension in parents, and other risk factors. J Clin Epidemiol. 1996;49:727-34.

28. Bloetzer C, Paccaud F, Burnier M, Bovet P, Chiolero A. Performance of parental history for the targeted screening of hypertension in children. J hypertension. 2015;33:1167-73.
29. Sidhu S, Sadhwani A, Mittal M, Sharma V, Sharma HB, Manna S. Hypertension in asymptomatic, young medical students with parental history of hypertension. $J$ Clin Diagnostic Res. 2017;11:CC05-CC08.

30. Yoo JE, Park HS. Relationship between parental hypertension and cardiometabolic risk factors in adolescents. J Clin Hypertension. 2017;19:678-83.

31. Yano Y, Lloyd-Jones DM. Isolated systolic hypertension in young and middleaged adults. Curr Hypertens Rep. 2016;18:78.

32. Jiang $X$, Kiel DP, Kraft P. The genetics of vitamin D. Bone. 2019;126:59-77.

33. Licht CM, De Geus EJ, Seldenrijk A, Van Hout HP, Zitman FG, Van Dyck R, et al. Depression is associated with decreased blood pressure, but antidepressant use increases the risk for hypertension. Hypertension. 2009;53:631-8.

34. Tamez H, Thadhani RI. Vitamin D and hypertension: an update and review. Curr Opin Nephrol hypertension. 2012;21:492-9.

35. Everett B, Zajacova A. Gender differences in hypertension and hypertension awareness among young adults. Biodemography Soc Biol. 2015;61:1-17.

36. Diaz KM, Shimbo D. Physical activity and the prevention of hypertension. Curr hypertension Rep. 2013;15:659-68.

37. Zhang D, Cheng C, Wang Y, Sun H, Yu S, Xue Y, et al. Effect of vitamin D on blood pressure and hypertension in the general population: an update meta-analysis of cohort studies and randomized controlled trials. Prev Chronic Dis. 2020;17:E03.

38. Cheng LT, Gao YL, Gu Y, Zhang L, Bi SH, Tang W, et al. Stepwise increase in the prevalence of isolated systolic hypertension with the stages of chronic kidney disease. Nephrol Dial Transpl. 2008;23:3895-900.

39. Bosworth C, de Boer IH. Impaired vitamin D metabolism in CKD. Semin Nephrol. 2013;33:158-68.

\section{AUTHOR CONTRIBUTIONS}

All authors contributed to this study, which was conceived by Y.C. and R.T.W., with statistical support from N.G. and M.W. and written by all authors (Y.C., M.W., N.G., S.S., S.A., L.J., and R.T.W.).

\section{COMPETING INTERESTS}

The authors declare no competing interests.

\section{ADDITIONAL INFORMATION}

Supplementary information The online version contains supplementary material available at https://doi.org/10.1038/s41371-021-00577-6.

Correspondence and requests for materials should be addressed to Y.L.C.

Reprints and permission information is available at http://www.nature.com/ reprints

Publisher's note Springer Nature remains neutral with regard to jurisdictional claims in published maps and institutional affiliations.

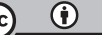

Open Access This article is licensed under a Creative Commons Attribution 4.0 International License, which permits use, sharing, adaptation, distribution and reproduction in any medium or format, as long as you give appropriate credit to the original author(s) and the source, provide a link to the Creative Commons license, and indicate if changes were made. The images or other third party material in this article are included in the article's Creative Commons license, unless indicated otherwise in a credit line to the material. If material is not included in the article's Creative Commons license and your intended use is not permitted by statutory regulation or exceeds the permitted use, you will need to obtain permission directly from the copyright holder. To view a copy of this license, visit http://creativecommons. org/licenses/by/4.0/.

(c) The Author(s) 2021 